\title{
A Study on the Causes for Child Trafficking using Indeterministic Trapezoidal Fuzzy Cognitive Maps
}

\author{
A.Praveen Prakash \\ Department of Mathematics \\ Hindustan University \\ Padur, Chennai-603103
}

\author{
M.P.Kannan \\ Department of Mathematics \\ Velammal,Mat, $\mathrm{Hr}, \mathrm{Sec}, \mathrm{School}$ \\ Mogappair, Chennai-600037
}

\author{
J.Esther Jerlin \\ Department of Mathematics \\ Hindustan University \\ Padur, Chennai-603103
}

\begin{abstract}
According to UNICEF, Child trafficking is defined as "any person under the age 18 who is recruited, transported, transferred, harboured or received for the purpose of exploitation, either within or outside a country". It has been mentioned in the article that children were missing overnight, as many as one every eight minutes, according to the National Crime Records Bureau. Children were trafficked for varied reasons. In this paper, we analyses the major causes for Child Trafficking and ranking the causes using the newly proposed fuzzy model Indeterministic Trapezoidal Fuzzy Cognitive Map. This model has an advantage of ranking the causes by the calculated membership value also showing the indeterminacy relation between the nodes obtained from the expert's. This paper has four sections. Section one deals with the overall existing problem of child trafficking. Section two deals with the description of the model. Section three gives the study and analysis of the problem using the prescribed model. Section four gives the conclusion and suggestion based on the study.
\end{abstract}

\section{Keywords}

FCMs, NCMs, TpNCMs, Hidden pattern, fixed point, Child Trafficking.

\section{INTRODUCTION}

The government of India figured out that for the year 20112012 , about 126,321 trafficked children were rescued from the domestic service and an increase of nearly $27 \%$ was seen year after year. The parents of the rescued children have no idea about their daughters what has happened to them. According to India's national Crime Record Bureau, a child goes missing in India every eight minutes, and more than a third are never found. The great difficulty is that most traffickers live one among the other people and many of the traffickers are women so that they find easy to move with the girls and get them trafficked. $[10,11]$

The newly proposed model helps in ranking the attributes in a refined manner. It involves the basis of FCM, NCM and TpFCM. FCM deals with the on-off state of the attributes. NCM deals with the indeterminacy condition between the attributes. TpFCM ranks the attributes based on the membership value obtained from Tp average. TpFCM relies on giving interrelationship degree value between the attributes though indeterminacy is seen between them. But this model have an advantage of using inderterminate condition by denoting I so that the membership value obtained from TpNCM average shows the minute difference in ranking than TpFCM.[6, 3]

\section{PRELIMINARIES}

The membership function of the Trapezoidal Fuzzy number $\tilde{A}=(\mathrm{a}, \mathrm{b}, \mathrm{c}, \mathrm{d})$ is given by, where $\mathrm{a} \leq \mathrm{b} \leq \mathrm{c} \leq \mathrm{d}$, Fuzzy Cognitive Maps has been introduced by Lotfi. A. Zadeh (1965). After a decade, Political scientist Axelord (1976) used this fuzzy model to study decision making in social and political systems. Later, Kosko (1986, 1988 and 1997) extended the cognitive maps using membership values and causalities between the nodes. FCM works on unsupervised data. It is a simple and effective tool to analyze social, economic, political problems etc. In this section we gives the basic definitions of Trapezoidal fuzzy number and its algebraic operations. And definitions of Trapezoidal Neutrosophic Cognitive Maps (TpFCM) are given.[1,2]

\subsection{Trapezoidal Fuzzy number and the Algebraic Operations}

\subsubsection{Trapezoidal Fuzzy number}

It is a fuzzy number represented with four points as follows. The membership function defined as

$\mu_{\breve{A}}(\mathrm{x})=\left\{\begin{array}{cc}0, & \mathrm{x}<\mathrm{a} \\ \frac{x-a}{b-a}, & \mathrm{a}<\mathrm{x} \leq \mathrm{b} \\ 1, & \mathrm{~b}<\mathrm{x}<\mathrm{d} \\ \frac{d-x}{d-c}, & \mathrm{c} \leq \mathrm{x}<\mathrm{d} \\ 0, & \mathrm{x}>\mathrm{d}\end{array}\right.$

\subsubsection{Operation of Trapezoidal Fuzzy Number}

The following are the four operations that can be performed on triangular fuzzy numbers: Let $\tilde{A}=(\mathrm{a}, \mathrm{b}, \mathrm{c}, \mathrm{d})$ and $\tilde{B}=$ $(\mathrm{e}, \mathrm{f}, \mathrm{g}, \mathrm{h})$ then,

$$
\begin{array}{ll}
\text { 1. } & \tilde{A}+\tilde{B}=(\mathrm{a}+\mathrm{e}, \mathrm{b}+\mathrm{f}, \mathrm{c}+\mathrm{g}, \mathrm{d}+\mathrm{h}) \\
\text { 2. } & \tilde{A}-\tilde{B}=(\mathrm{a}-\mathrm{h}, \mathrm{b}-\mathrm{g}, \mathrm{c}-\mathrm{f}, \mathrm{d}-\mathrm{e}) \\
\text { 3. } & \tilde{A} \times \tilde{B}=(\mathrm{ae}, \mathrm{bf}, \mathrm{cg}, \mathrm{dh}) \\
\text { 4. } & \frac{1}{\widetilde{A}}=\left(\frac{1}{d}, \frac{1}{c}, \frac{1}{b}, \frac{1}{a}\right)
\end{array}
$$

2.1.3 Degrees of the Trapezoidal Fuzzy Number The linguistic values of the trapezoidal fuzzy numbers are 
Table 1. Table captions should be placed above the table

\begin{tabular}{|l|l|}
\hline Very Low & $(0,0.11,0.21,0.31)$ \\
\hline Low & $(0.21,0.31,0.41,0.51)$ \\
\hline Medium & $(0.41,0.51,0.61,0.71)$ \\
\hline High & $(0.61,0.71,0.81,0.91)$ \\
\hline Very High & $(0.81,0.91,1,1)$ \\
\hline
\end{tabular}

\subsection{Basic Definitions of Indeterministic}

\section{Trapezoidal Fuzzy Cognitive Maps (TpNCMs)}

2.2.1 Definition: In the neutrosophic logic every logical variable $\mathrm{x}$ is described by an ordered triple $\mathrm{x}=(\mathrm{T}, \mathrm{I}, \mathrm{F})$ where $\mathrm{T}$ is the degree of truth, $\mathrm{F}$ is the degree of false and I level of ideterminacy.

2.2.2 Definition: A Neutrosophic Cognitive Map (NCM) is a neutrosophic directed graph with concepts like policies, events etc. as nodes and causalities or indeterminates as edges. It represents the causal relationship between concepts.

Let $C_{1}, C_{2}, \ldots C_{n}$ denote $n$ nodes, further we assume each node is a neutrosophic vector from neutrosophic vector space V. So a node $\mathrm{C}_{\mathrm{i}}$ will be represented by $\left(\mathrm{x}_{1}, \ldots\right.$, $x_{n}$ ) where $x_{k}$ 's are zero or one or I (I is the indeterminate) and $x_{k}=1$ means that the node $C_{k}$ is in the on state and $x_{k}=0$ means the node is in the off state and $x_{k}=I$ means the nodes state is an indeterminate at that time or in that situation. Let $\mathrm{C}_{\mathrm{i}}$ and $\mathrm{C}_{\mathrm{j}}$ denote the two nodes of the NCM. The directed edge from $C_{i}$ to $C_{j}$ denotes the causality of $\mathrm{C}_{\mathrm{i}}$ on $\mathrm{C}_{\mathrm{j}}$ called connections. Every edge in the NCM is weighted with a number in the set $\{-1,0,1, I\}$. Let $e_{i j}$ be the weight of the directed edge $C_{i} C_{j}, e_{i j} \in\{-1,0,1, I\} . e_{i j}=0$ if $\mathrm{C}_{\mathrm{i}}$ does not have any effect on $\mathrm{C}_{\mathrm{j}}, \mathrm{e}_{\mathrm{ij}}=1$ if increase (or decrease) in $\mathrm{C}_{\mathrm{i}}$ causes increase (or decreases) in $\mathrm{C}_{\mathrm{j}}$, $\mathrm{e}_{\mathrm{ij}}$ $=-1$ if increase (or decrease) in $\mathrm{C}_{\mathrm{i}}$ causes decrease (or increase) in $C_{j} \cdot e_{i j}=I$ if the relation or effect of $C_{i}$ on $C_{j}$ is an indeterminate. [3]

\subsection{Basic Definitions of Trapezoidal Neutrosophic Cognitive Maps (TpNCMs)}

2.3.1 Definition: Trapezoidal NCMs with edge weights or causalities from the set $\{-1,0,1$, I $\}$ are called simple Trapezoidal NCMs.

2.3.2 Definition: A TpNCM is a directed graph with concepts like policies, events etc, as nodes and causalities as edges, It represents causal relationships between concepts.

2.3.3 Definition: Consider the nodes/concepts ${ }_{\mathrm{Tp}} \mathrm{C}_{1}$, ${ }_{\mathrm{Tp}} \mathrm{C} 2, \ldots, \mathrm{Tp}_{\mathrm{p}} \mathrm{Cn}$ of the Trapezoidal NCM. Suppose the directed graph is drawn using edge weight ${ }_{T p}$ eije $\{-1,0,1, \mathrm{I}\}$. The Trapezoidal neutrosophic matrix $\mathrm{M}$ be defined by $\operatorname{TpN}(\mathrm{M})=$ $\left(_{T p}\right.$ eij) where ${ }_{T p}$ eij is the Trapezoidal neutrosophic weight of the directed edge ${ }_{T p} C_{i T p} C_{j}$. Tp(M) is called the adjacency matrix of Trapezoidal Neutrosophic Cognitive Maps, also known as the connection matrix of the TpNCM. It is important to note that all matrices associated with a TpNCM are always square matrices with diagonal entries as zero.

2.3.4 Definition: Let $\mathrm{TpC}_{1}, \mathrm{TpC}_{2}, \ldots, \mathrm{TpCn}$ be the nodes of an TpNCM. $A=\left(a_{1}, a_{2}, \ldots, a_{n}\right)$ where Tpeije $\{-1,0,1, I\} . A$ is called the instantaneous state vector and it denotes the on-off position of the node at an instant.
Instantaneous vector

$a_{i}=0$ if $a_{i}$ is off (has no effect)

$\mathrm{a}_{\mathrm{i}}=1 \quad$ if $\mathrm{a}_{\mathrm{i}}$ is on, (has effect)

$a_{i}=I \quad$ if $a_{i}$ is indeterminate, (effect cannot be determined) where $\mathrm{i}=1,2, \ldots, \mathrm{n}$.

2.3.5 Definition: Let $\mathrm{TpC}_{1}, \mathrm{TpC}_{2}, \ldots, \mathrm{TpC}_{\mathrm{n}}$ be the nodes of TpNCM. Let be the edges of the TpNCM $(i \neq j)$. Then the edges form a directed cycle a TpNCM is said to be cyclic if it possesses a directed cycle. A TpNCM is said to be acyclic if it does not possess any directed cycle.

2.3.6 Definition: A TpNCM is said to be cyclic is said to have a feedback.

2.3.7 Definition: When there is a feedback in an TpNCM, i.e., when the causal relations flow through a cycle in a revolutionary way, the TpNCM is called a dynamical system.

2.3.8 Definition: Let ${\overrightarrow{\mathrm{TCC}_{1} \mathrm{TpC}_{2}}}_{\mathrm{TpC}_{2} \mathrm{TpC}_{3}}, \ldots \ldots ., \mathrm{TpC}_{\mathrm{n}}$ ${ }_{1} \mathrm{TpC}_{\mathrm{n}}$ be a cycle. When $\mathrm{TpCi}$ is switched $\mathrm{ON}$ and if the causality flows through the trapezoidal edges of a cycle and if it again causes $\mathrm{Ci}$, we say that the dynamical system goes round and round. This is true for any trapezoidal node $\mathrm{TpCi}$ for $\mathrm{i}=1,2, \ldots, \mathrm{n}$. The equilibrium state for this dynamical system is called the hidden pattern.

2.3.9 Definition: If the equilibrium state of a dynamical system is a unique state vector, then it is called a fixed point. Consider a $\mathrm{TpNCM}$ with $\mathrm{TpC}_{1}, \mathrm{TpC}_{2}, \ldots, \mathrm{TpCn}$ as nodes. For example let us start the dynamical system by switching on $\mathrm{TpC}_{1}$.Let us assume that the TpNCM settles down with $\mathrm{TpC} 1$ and $\mathrm{TpCn} \mathrm{ON}$ i.e., in the state vector remains as $(1,0,0, \ldots, 0)$ is called fixed point.

2.3.10 Definition: If the TpNCM settles down with a state vector repeating in the form $A_{1} \rightarrow A_{2} \rightarrow \ldots \rightarrow A_{i} \rightarrow A_{1}$ then this equilibrium is called a limit cycle.

\subsection{Algorithm used to manipulate TpNCM}

Step 1: Consider the attributes given by the experts for the problem as $\mathrm{TpC}_{1}, \mathrm{TpC}_{2}, \ldots . \mathrm{TpC}_{\mathrm{n}}$. According to the feedback given by the expert directed graph is drawn.

Step 2: Let $\mathrm{TpN}(\mathrm{M})$ denotes the connection matrix with \{$1,0,1, \mathrm{I}\}$ as causalities.

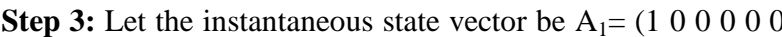
$\left.\begin{array}{llll}0 & 0 & 0 & 0\end{array}\right)$. It is passed into $\mathrm{TpN}(\mathrm{M})$. The on state vector $\operatorname{TpN}(\mathrm{M})_{\text {avgweight }}$ is obtained.

Step 4: Maximum membership value is threshold as 1 and other as 0 and I. Consider the threshold and updated vector as $\mathrm{A}_{2}$.

Step 5: $A_{2}$ is passed into $T p N(M)$ the above said calculation is performed, threshold and updated until the same fixed point is obtained. [5]

\section{ANALYSIS OF THE PROBLEM}

A study on the problem has been made by interviewing the trafficked children and the members of NGO in India. The following ten attributes obtained from the experts were considered for the analysis of the problem. [7]

$\mathrm{TpC}_{1}$ - Entertainment

$\mathrm{TpC}_{2}$ - Illiteracy

$\mathrm{TpC}_{3}$ - Unemployment 
$\mathrm{TpC}_{4}$ - Poverty

$\mathrm{TpC}_{5}$-Sexual Exploitation

$\mathrm{TpC}_{6}$ - Bonded Labour

$\mathrm{TpC}_{7}$ - Political Uprising

$\mathrm{TpC}_{8^{-}}$Illegal Activities

$\mathrm{TpC}_{9}$ - Social Factorr

$\mathrm{TpC}_{10^{-}}$High profit at low risk

Now we reformulate a different format of the questionnaire where we permit the expert to give answers like the relation between certain nodes is indeterminable or not known. Now based on the expert's opinion also about the notion of indeterminacy we obtain the following Trapezoidal Neutrosophic connection matrix $\mathrm{TpN}(\mathrm{E})$ from Fig 1. [9,8]

$\left.\begin{array}{c|cccccccccc}\hline 1 & T p C 1 & T p C 2 & \mathrm{TpC3} & \mathrm{TpC4} & \mathrm{TpC5} & \mathrm{TpC6} & \mathrm{TpC7} & \mathrm{TpC8} & \mathrm{TpC9} & \mathrm{TpC10} \\ T p C 1 & 0 & V H & L & M & H & H & M & V L & I & V L \\ T p C 2 & M & 0 & V H & H & M & H & M & L & V L & L \\ T p C 3 & V H & M & 0 & H & M & L & V L & M & H & L \\ T p C 4 & L & M & L & 0 & H & H & M & I & V L & V H \\ T p C 5 & V L & L & L & H & 0 & M & L & V H & I & H \\ T p C 6 & V L & L & H & M & V H & 0 & H & L & V L & H \\ T p C 7 & M & H & L & M & V L & H & 0 & M & V H & H \\ T p C 8 & V L & M & H & H & M & L & V L & 0 & L & V H \\ T p C 9 & H & H & L & V L & M & L & V L & V H & 0 & M \\ T p C 10 & V L & M & L & H & H & M & L & V H & V L & 0\end{array}\right]$

Fig 1: Trapezoidal Neutrosophic Connection Matrix

The corresponding Trapezoidal Average weight matrix $\left(\mathrm{TpN}(\mathrm{M})_{\text {avgweight }}\right)$ is given below in Fig 2.

$\left.\begin{array}{cccccccccccc}\square & T p C 1 & T p C 2 & T p C 3 & T p C 4 & T p C 5 & T p C 6 & T p C 7 & T p C 8 & T p C 9 & T p C 10 \\ T p C 1 & 0 & 0.93 & 0.36 & 0.56 & 0.76 & 0.76 & 0.56 & 0.16 & I & 0.16 \\ T p C 2 & 0.56 & 0 & 0.93 & 0.76 & 0.56 & 0.76 & 0.56 & 0.36 & 0.16 & 0.36 \\ T p C 3 & 0.93 & 0.56 & 0 & 0.76 & 0.56 & 0.36 & 0.16 & 0.56 & 0.76 & 0.36 \\ T p C 4 & 0.36 & 0.56 & 0.36 & 0 & 0.76 & 0.76 & 0.56 & I & 0.16 & 0.93 \\ T p C 5 & 0.16 & 0.36 & 0.36 & 0.76 & 0 & 0.56 & 0.36 & 0.93 & I & 0.76 \\ T p C 6 & 0.16 & 0.36 & 0.76 & 0.56 & 0.93 & 0 & 0.76 & 0.36 & 0.16 & 0.76 \\ T p C 7 & 0.56 & 0.76 & 0.36 & 0.56 & 0.16 & 0.76 & 0 & 0.56 & 0.93 & 0.76 \\ T p C 8 & 0.16 & 0.56 & 0.36 & 0.76 & 0.56 & 0.36 & 0.16 & 0 & 0.36 & 0.93 \\ T p C 9 & 0.76 & 0.76 & 0.36 & 0.16 & 0.56 & 0.36 & 0.16 & 0.93 & 0 & 0.56 \\ T p C 10 & 0.16 & 0.56 & 0.36 & 0.76 & 0.76 & 0.56 & 0.36 & 0.93 & 0.16 & 0\end{array}\right]$

\subsection{First Process}

When the node $\mathrm{TpC}_{1}$ i.e "Entertainment" is in on state and other nodes in off state we carry the above said procedures to obtain the fixed point as the result.

$\mathrm{A}_{0}=(1000000000)$

$\mathrm{A}_{0} \mathrm{TpN}(\mathrm{M})_{\text {avgweight }}=\left(\begin{array}{lllllll}0 & 0.93 & 0.36 & 0.56 & 0.76 & 0.76 & 0.56\end{array}\right.$ 0.16 I 0.16 )

$\longrightarrow\left(\begin{array}{llllllllll}0 & 1 & 0 & 0 & 0 & 0 & 0 & 0 & \mathrm{I} & 0\end{array}\right)=\mathrm{A}_{1}$

$\mathrm{A}_{1} \mathrm{TpN}(\mathrm{M})_{\text {avgweight }}=\left(\begin{array}{lll}0.56+0.76 \mathrm{I} & 0+0.76 \mathrm{I} & 0.93\end{array}\right.$

$\begin{array}{llll}+0.36 \mathrm{I} & 0.76+0.16 \mathrm{I} & 0.56+0.56 \mathrm{I} & 0.76+0.36 \mathrm{I}\end{array}$

$0.56+0.16 \mathrm{I} \quad 0.36+0.93 \mathrm{I} \quad 0.16+0 \mathrm{I} \quad 0.36+0.56 \mathrm{I})$

$\longrightarrow \quad\left(\begin{array}{llllllllll}0 & \mathrm{I} & 1 & 0 & 0 & 0 & 0 & 0 & 0 & 0\end{array}\right)=\mathrm{A}_{2}$

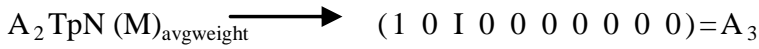

$\left.\mathrm{A}_{3} \mathrm{~A}_{2} \mathrm{TpN}(\mathrm{M})_{\text {avgweight }} \longrightarrow \mathrm{I} 100000000 \mathrm{I} 0\right)=\mathrm{A}_{4}$

$\mathrm{A}_{4} \quad \mathrm{~A}_{2} \mathrm{TpN}(\mathrm{M})_{\text {avgweight }} \longrightarrow\left(\begin{array}{lllllllll}0 & \mathrm{I} & 1 & 0 & 0 & 0 & 0 & 0 & 0\end{array}\right.$ $0)=\mathrm{A}_{5}=\mathrm{A}_{2}$

Therefore $\mathrm{A}_{2}$ is the fixed point i.e ( $\begin{array}{lllllll}0 & \mathrm{I} & 1 & 0 & 0 & 0 & 0\end{array}$ $\left.\begin{array}{lll}0 & 0 & 0\end{array}\right)$.

\subsection{Second Process}

When the node $\mathrm{TpC}_{4}$ i.e"Poverty" is in on state and other nodes in off state, we obtain the following instantaneous state vector.

$\mathrm{A}_{0}=(0001000000)$

$\mathrm{A}_{0} \mathrm{TpN}(\mathrm{M})_{\text {avgweight }}$ $=\mathrm{A}_{1}$

$\mathrm{A}_{1} \mathrm{TpN}(\mathrm{M})_{\text {avgweight }}$ $=\mathrm{A}_{2}$

$\mathrm{A}_{2} \mathrm{TpN}(\mathrm{M})_{\text {avgweight }}$

$\left(\begin{array}{llllllllll}0 & 0 & 0 & 0 & 0 & 0 & 0 & \text { I } & 0 & 1\end{array}\right)$

$=\mathrm{A}_{3}=\mathrm{A}_{1}$

Therefore $A_{1}$ is the fixed point i.e $\left(\begin{array}{lllllll}0 & 0 & 0 & 0 & 0 & 0 & 0\end{array}\right.$ I $\left.0 \begin{array}{ll}0 & 1\end{array}\right)$.

The following table shows the weightage of the attributes calculated using the above said algorithm of TpNCM.

Table 2: Weightage of the attributes

\begin{tabular}{|c|c|c|c|c|c|c|c|c|c|c|}
\hline Attributes & $\mathrm{Tp}_{1}$ & $\mathrm{TpC}_{2}$ & TpC3 & $\mathrm{TpC}_{4}$ & $\mathrm{Tp}_{5}$ & $\mathrm{TpC}_{6}$ & TpC? & $\mathrm{TpC}_{s}$ & TpC, & $\mathrm{TpC}_{10}$ \\
\hline $\mathrm{TpC}_{1}$ & 0.56 & I & 0.93 & 0.76 & 0.56 & 0.76 & 0.56 & 0.36 & 0.16 & 0.36 \\
\hline $\mathrm{TpC}_{2}$ & 0.56 & I & 0.93 & 0.76 & 0.56 & 0.76 & 0.56 & 0.36 & 0.16 & 0.36 \\
\hline $\mathrm{TpC}_{3}$ & 0.56 & I & 0.93 & 0.76 & 0.56 & 0.76 & 0.56 & 0.36 & 0.16 & 0.36 \\
\hline $\mathrm{TpC}_{4}$ & 0.16 & 0.56 & 0.76 & 0.76 & \begin{tabular}{|l}
0.56 \\
\end{tabular} & 0.16 & 0.16 & I & 0.36 & 0.93 \\
\hline $\mathrm{TpC}_{5}$ & 0.16 & 0.56 & 0.76 & 0.76 & 0.56 & 0.16 & 0.16 & I & 0.36 & 0.93 \\
\hline $\mathrm{TpC}_{6}$ & 0.16 & 0.56 & 0.76 & 0.76 & 0.56 & 0.16 & 0.16 & I & 0.36 & 0.93 \\
\hline $\mathrm{TpC}_{7}$ & 0.16 & 0.56 & 0.36 & 0.76 & 0.76 & 0.36 & 0.36 & 0.93 & 0.16 & 0 \\
\hline $\mathrm{TpC}_{8}$ & 0.16 & 0.56 & 0.36 & 0.76 & 0.76 & 0.36 & 0.36 & 0.93 & 0.16 & 0 \\
\hline TpC9 & 0.16 & 0.56 & 0.36 & 0.76 & 0.76 & 0.36 & 0.36 & 0.93 & 0.16 & 0 \\
\hline $\mathrm{TpC}_{10}$ & 0.16 & 0.56 & 0.76 & 0.76 & 0.56 & 0.16 & 0.16 & 0.93 & 0.36 & 0.93 \\
\hline $\begin{array}{l}\text { Total } \\
\text { Weight }\end{array}$ & 2.8 & 3.92 & 6.91 & 7.6 & 6.2 & 4 & 3.4 & 4.8 & 2.4 & \begin{tabular}{|l|}
4.8 \\
\end{tabular} \\
\hline $\begin{array}{l}\text { Average } \\
\text { value }\end{array}$ & 0.28 & 0.392 & 0.691 & 0.76 & 0.62 & 0.4 & 0.34 & 0.48 & 0.24 & 0.48 \\
\hline
\end{tabular}

\section{CONCLUSIONS AND SUGGESTIONS}

From the above table it is clear that the indeterminate relation between the nodes play a vital role in calculating the accurate total weight of the attributes in correspondence with the other. From the calculated average value ranking of the dominant causes are done. Poverty -0.76, Unemployment-0.691, Sexual Exploitation -0.62, High profit at low risk and Illegal Activities-0.48, Bonded Labour- 0.48, Illiteracy-0.392, Political Uprising- 0.34, Entertainment - 0.28, Social Factor0.24 .

The government can conduct awareness program to develop and make each individual to realize their responsibilities and duties to the society. Volunteers can organize an antitrafficking committee and collect fund for the welfare measures against trafficking.

\section{REFERENCES}

[1] Kaufmann, "Introduction to the Theory of Fuzzy Subsets", Academic Press, INC. (LONDON) LTD, 1975.

[2] Kosko, "Neural Networks and Fuzzy systems: A Dynamical System Approach to Machine Intelligence", Prentice Hall of India, 1997.

[3] W.B Vasantha Kandasamy and Smarandache Florentin; 'Fuzzy Cognitive Maps and Neutrosophic Cognitive Maps', Xiquan, Phoenix. (2003).

[4] H.J. Zimmermann, "Fuzzy Set Theory and its application", Fourth Edition Springer 2011. 
[5] M.Clement Joe Anand, A.Victor Devadoss, "Using new Triangular Fuzzy Cognitive Maps(TRFCM) to analyze causes of Divorce in Family", International Journal of Communications and networking Systems vol 02,pages;205-213, (IIR)205.

[6] A.Praveen Prakash, J.Esther Jerlin and J.Bennilo Fernandes, "A Study on the causes for aversion to mathematics by engineering students using Fuzzy Cognitive Maps" (FCMs), International Journal of Innovative Research in Science, Engineering and Technology, ISSN: 2319-8753, Vol. 3, Issue 3, March 2014.

[7] A.Praveen Prakash , M.P Kannan and Kirubakaran, " $A$ Study on the causes for Child Trafficking using Fuzzy Cognitive Maps" (FCMs), IMRF Publications for Mathematical Sciences International Research Journal, ISSN:2278-8697, ISBN:978-93-84124-03-8, Vol. 3, Issue 1, March 2014
[8] A.Praveen Prakash, N.Lakshmipathy and J.Esther Jerlin, "Problems of Housemaids in Chennai City A Study Using Combined Fuzzy Cognitive Maps" (CFCMs), International Association of Engineers, ISBN: 978-98819252-7-5, ISSN: 2078-0958, ISSN-2078-0966, Vol.IJuly 2014.

[9] A.Praveen Prakash , M.P Kannan and Esther Jerlin.J, “ $A$ Study on the causes for Child Trafficking using Combined Fuzzy Cognitive Maps" (CFCMs), ELSEVIER, ISBN: 978-93-51072-61-4, September 2014.

[10] Trafficking of children in Wikipedia

[11] Child Trafficking in Times of India

[12] A.Rajkumar, A.Victor Devadoss, “ A study on Miracles through Holy Bible using new Triangular Neutrosophic Cognitive Maps (TRNCMs)", IJCA, Issue-4, Vol-4, JulyAugust-2014. 